\title{
Supplemental maternal oxygen therapy during Caesarean section under epidural anaesthesia: a comparison of nasal prongs and facemask
}

Forty healthy parturients at term, undergoing elective Caesarean section, were divided into two groups to receive supplemental oxygen by either simple facemask (Group FM, $8 \mathrm{~L} \cdot \mathrm{min}^{-1}$ ) or nasal prongs (Group NP, $4 \mathrm{~L} \cdot \mathrm{min}^{-1}$ ) during the procedure. Anaesthesia was provided by epidural block to equivalent dermatomal levels in all patients. Maternal oxygen saturation was measured continuously with pulse oximetry and supplemental oxygen was provided to the mother after administration of the epidural test dose and continued until the end of the procedure. Following delivery of the infant and concurrent with Apgar scoring, the umbilical cord was double-clamped and arterial and venous samples were drawn. The $\mathrm{pH}$, partial pressures of $\mathrm{O}_{2}$ and $\mathrm{CO}_{2}$ and $\mathrm{O}_{2}$ saturations were measured. There was no difference in the clinical condition of the neonates, as assessed by Apgar scores, or in the acid-base and oxygenation status, as assessed by blood gas analyses between the two groups. Mean umbilical vein oxygen saturation, a measure of fetal oxygen delivery, was $46 \pm 18 \%$ (95\% confidence interval $39 \%$ to $54 \%$ ) for Group NP and $54 \pm 17 \%$ (95\% confidence interval $46 \%$ to $62 \%$ ) for Group FM, again not different. We conclude that when the clinical condition, acid-base and oxygen-

\section{Key words}

ANAESTHESIA: obstetric;

OXYGEN: delivery systems;

SURGERY: Caesarean section.

From the Departments of Anaesthesia, *Ottawa General Hospital, University of Ottawa, 501 Smyth Road, Ottawa, Ontario, K1H 8 L6 and †Women's College Hospital, University of Toronto, 76 Grenville Street, Toronto, Ontario, M5S 1B2.

Address correspondence to: Dr. E. Crosby.

Presented in part at the Canadian Anaesthetists' Society Annual Meeting, June, 1990, Vancouver, British Columbia, Canada.

Accepted for publication 6th December, 1991. ation status of neonates, delivered by elective Caesarean section to healthy, low-risk parturients with normal placental function under epidural anaesthesia, are evaluated, it makes no difference whether the mothers received supplemental oxygen by nasal prongs or simple facemask.

Quarante parturientes saines, à terme et programmées pour une césarienne ont été réparties en deux groupes : un devant recevoir un supplément d'oxygène durant l'intervention au moyen d'une simple masque facial (Group $F M, 8 \mathrm{~L} \cdot \mathrm{min}^{-1}$ ) et l'autre au moyen de "lunettes " nasales (Group NPO, 4 $\left.L \cdot \mathrm{min}^{-1}\right)$. L'anesthésie était réalisée au moyen d'un block épidural atteignant des niveaux sensitifs identiques pour toutes les patientes. La saturation maternelle en oxygène était constamment mesurée au moyen d'un saturomètre et un supplément d'oxygène était administré à la mère après l'administration de la dose test de l'épidurale et maintenu jusqu'à la fin de l'intervention chirurgicale. Après l'accouchement et concurremment à l'évaluation du score d'Apgar, un double clampage du cordon ombilical était effectué et des échantillons artériels et veineux prélevés. Le pH, les pressions partielles en $\mathrm{O}_{2}$ et en $\mathrm{CO}_{2}$ et les saturations en oxygène ont été mesurés. Entre ces deux groupes, il n'y a pas eu de différence de condition clinique pour les nouveaux-nés, telle qu'évaluée par le score d'Apgar, ou de l'équilibre acido-basique et de l'oxygénation, tels qu'évaluéspar la gazométrie sanguine. La saturation moyenne en oxygène de sang ombilical veineux, une mesure du transport en oxygène chez le foetus, était de $46 \pm 18 \%$ (intevalle de confiance à 95\% : 39\% à 54\%) pour le Group NP et de $54 \pm 17 \%$ (intervalle de confiance à $95 \%$ : 46 à $62 \%$ ) pour le Group FM, et, encore une fois, ne présentait pas de différence. Nous concluons que lorsqu'on évalue la condition clinique, l'équilibre acido-basique et l'oxygénation, chez les nouveaux-nés de parturientes saines, à faible risque, présentant une fonction placentaire normale et accouchées par césarienne non urgente sous anesthésie épidurale, il n'y a pas de difference entre un simple masque facial et les "lunettes" nasales comme mode d'administration d'un supplément d'oxygène. 
It is current practice, during Caesarean section under epidural anaesthesia, to provide the mother with a source of supplemental oxygen, at least until delivery of the infant. It is known that maternal and fetal arterial oxygen partial pressures $\left(\mathrm{PO}_{2}\right)$ increase with increasing maternal inhaled oxygen concentration $\left(\mathrm{FIO}_{2}\right)$. It is recognized that there is a graded maternal and fetal $\mathrm{PO}_{2}$-response to increasing maternal $\mathrm{FIO}_{2}$ such that as maternal $\mathrm{FIO}_{2}$ is increased, there is a concurrent and proportionate increase in both maternal and foetal blood oxygen pressures and content. Clinically, this results in more acceptable fetal acid-base variables at birth and infants who initiate spontaneous respirations sooner after birth than in the newborns of mothers breathing air during Caesarean section. ${ }^{1,2}$ In the woman with a normal pregnancy undergoing Caesarean section, it is usually felt to be acceptable to provide the mother with supplemental oxygen via a lowflow oxygen system. The system most commonly used is that of a disposable, clear plastic face mask but many patients find these masks uncomfortable to wear, complaining of claustrophobic sensations or difficulty in "getting enough air." The use of nasal prongs to deliver supplemental oxygen is advocated by some anaesthetists who feel that these masks are better tolerated and as effective in providing appropriate supplements of oxygen. Oxygen flows administered through the mask are typically 6-8 L $\cdot \mathrm{min}^{-1}$ and through the nasal prongs are 2-4 $\mathrm{L} \cdot \mathrm{min}^{-1}$. More than $4 \mathrm{~L} \cdot \mathrm{min}^{-1}$ administered through nasal prongs usually results in considerable drying of the respiratory mucosa and is not well tolerated. Although 8 $\mathrm{L} \cdot \mathrm{min}^{-1}$ of oxygen delivered by mask would be expected to provide a higher maternal $\mathrm{FIO}_{2}$ than $4 \mathrm{~L} \cdot \mathrm{min}^{-1}$ by nasal prongs, the resultant umbilical venous and arterial oxygen pressures and saturations and Apgar scores at birth, in infants of mothers undergoing Caesarean section under epidural anaesthesia and treated with these two systems have not been compared.

Umbilical arterial and venous blood may be sampled from a double-clamped portion of the umbilical cord after delivery of the infant and measurements of arterial and venous oxygen saturations provide a measure of both oxygen delivery (umbilical vein oxygen saturation, $\mathrm{SuvO}_{2}$ ) and utilization (umbilical vein minus umbilical arterial oxygen saturation, $\mathrm{SuvO}_{2}-\mathrm{SuaO}_{2}$ ). By comparing $\mathrm{SuvO}_{2}$ in samples obtained from newborns whose mothers received supplemental oxygen by either mask or prongs, differences in oxygen delivery to the fetus may be assessed and the relative efficacy of the two systems in delivering oxygen to the fetus may be determined.

It is our hypothesis that the use of nasal prongs would result in umbilical blood oxygen pressures and saturations, acid-base balance and overall clinical conditions that are not different from those achieved with oxygen masks. Our second hypothesis is that the nasal prongs would be more acceptable to most patients, causing less discomfort.

\section{Methods}

The protocol was approved by the hospital ethics and human experimentation committee. Written, informed consent was obtained from 40 healthy (ASA physical status 1) patients presenting for elective Caesarean section under epidural anaesthesia. Patients with diabetes mellitus, chronic hypertension and pregnancy-associated hypertension were excluded as were other patients with conditions that might result in altered placental blood supply or function. Patients were randomly assigned to one of two groups: Patients in Group NP received nasal prongs with $4 \mathrm{~L} \cdot \mathrm{min}^{-1}$ of oxygen flow and those in Group FM received simple facemasks (Hudson ${ }^{\circledR}$ See-thru ${ }^{\circledR}$ Adult Oxygen Mask, Hudson ${ }^{\circledR}$ Oxygen Therapy Sales Company, Temecula, Calif, USA) with $8 \mathrm{~L} \cdot \mathrm{min}^{-1}$ of oxygen. Oxygen therapy was initiated after the epidural test dose was administered and continued until the end of surgery. All patients received epidural anaesthesia using incremental doses of carbonated lidocaine with $5 \mu \mathrm{g} \cdot \mathrm{ml}^{-1}$ epinephrine to $\mathrm{a}_{4}$ level of anaesthesia. All patients were supine with the uterus tilted to the left. Parturients were monitored continuously with an ECG and a pulse oximeter and maternal blood pressure was taken and recorded every two minutes intraoperatively with an automated blood pressure cuff. Maternal hypotension was considered to be present if a blood pressure $<100 \mathrm{mmHg}$ systolic or a decrease in BP $>20 \%$ than pre-epidural values occurred and was treated with small intravenous increments of ephedrine. After delivery of the infant, the umbilical cord was doubleclamped, an umbilical artery and vein were identified, a blood sample was drawn from each, labelled and iced. Oxygen and carbon dioxide partial pressures, oxygen saturation and $\mathrm{pH}$ were measured in each sample. At the end of the procedure, the mother was asked, in a standard fashion, whether or not the $\mathrm{O}_{2}$ device was comfortable to wear.

The following data were collected: maternal height, weight, and gestational age; fetal presentation; maternal $\mathrm{O}_{2}$ saturation before $\mathrm{O}_{2}$ therapy, after initiation of $\mathrm{O}_{2}$ therapy and at delivery; incidence of maternal hypotension; uterine incision-delivery time; umbilical venous and arterial $\mathrm{PO}_{2}$, $\mathrm{SO}_{2}, \mathrm{pH}, \mathrm{PCO}_{2}$; and Apgar scores. Finally, the maternal comfort with the oxygen system was recorded.

The primary outcome measurement compared between the two groups was the umbilical venous oxygen saturation $\left(\mathrm{SuvO}_{2}\right)$ since this is a measure of $\mathrm{O}_{2}$ delivery to the fetus. The sample size was chosen on the basis of previously published data, ${ }^{3}$ the assumption that a $\mathrm{SuvO}_{2}$ difference between the two groups of 5\% or more would be clinically important and an acceptance of a power of 0.8 . Data were 
TABLE I Demographics

\begin{tabular}{|c|c|c|c|}
\hline & Nasal prongs & Face mask & $P$ \\
\hline$n$ & 20 & 20 & NS \\
\hline Gestation & $39 \pm 1$ & $39 \pm 1$ & NS \\
\hline $\operatorname{Breech}(n)$ & 2 & 7 & NS \\
\hline MAT $\mathrm{O}_{2}$ SAT (PRE EPI) & $98 \pm 1.2$ & $98 \pm 1.0$ & NS \\
\hline MAT $\mathrm{O}_{2}$ SAT (Delivery) & $99 \pm 1$ & $99 \pm 0.7$ & NS \\
\hline Hypotension (\%) & 25 & 25 & NS \\
\hline UT incision-DEL Sec & $118 \pm 58$ & $134 \pm 64$ & NS \\
\hline
\end{tabular}

Values given are mean $\pm S D$.

analyzed using chi-square, Fisher's exact test and paired and unpaired Student's t tests. A $P$ value $<0.05$ was considered statistically significant.

\section{Results}

There were no differences between the groups with respect to maternal demographic data (Table I). However, there were two primary Caesarean sections for breech presentation in Group NP and seven in Group FM and this may have been responsible for the trend towards a longer incision-delivery time in Group FM. Hypotension, defined as a systolic blood pressure less than $100 \mathrm{mmHg}$ or a decrease from control value of greater than $20 \%$, occurred with equal frequency in both groups and was treated. Maternal oxygen saturation was increased in both groups by $\mathrm{O}_{2}$ therapy $(P<0.01)$ but there was no difference between the groups at any time. The neonatal data are presented in Table II. There were no differences between the two groups with respect to weight, Apgar scores at one and five minutes or acid-base data including arterial and venous $\mathrm{pH}$, oxygen partial pressures and saturation (Table II). A 95\% confidence interval (CI) for $\mathrm{SuvO}_{2}$, our primary outcome variable, was $(39 \%, 54 \%)$ for Group NP and $(46 \%, 62 \%)$ for Group FM. A 95\% CI for $\mathrm{PuvO}_{2}$ was $(3.3$ $\mathrm{kPa}, 4.1 \mathrm{kPa})$ for Group NP and $(3.8 \mathrm{kPa}, 4.7 \mathrm{kPa})$ for Group FM.

Two women in each group found the oxygen delivery device to be uncomfortable.

\section{Discussion}

The rationale for providing supplemental oxygen to the mother during Caesarean section is to improve fetal acidbase status and oxygenation at birth. Improved acid-base status and fetal oxygenation enhance fetal adaptation to extra-uterine life by decreasing time to sustained respiration. This has been shown to be true for Caesarean sections performed using both general and epidural anaesthesia. ${ }^{1,2}$ Increasing maternal $\mathrm{FIO}_{2}$ results in higher maternal $\mathrm{PaO}_{2}$ and elevates the transplacental oxygen gradient, the effect being higher fetal $\mathrm{PuvO}_{2}$ and $\mathrm{PuaO}_{2}$. This is seen whether the mother is breathing spontaneously
TABLE II Neonatal data

\begin{tabular}{lccc}
\hline & Nasal prongs & Face mask & $P$ \\
\hline Weight (g) & $3364 \pm 493$ & $3730 \pm 571$ & NS \\
Apgar 1 min $<7$ & 2 & 3 & NS \\
Apgar 5 min $<9$ & 1 & 1 & NS \\
pHua & $7.28 \pm 0.08$ & $7.27 \pm 0.04$ & NS \\
$\mathrm{PuaO}_{2} \mathrm{kPa}$ & $2.1 \pm 0.6$ & $1.9 \pm 0.5$ & NS \\
$\quad(\mathrm{mmHg})$ & $(16 \pm 4.5)$ & $(14 \pm 4)$ & \\
$\mathrm{SuaO}_{2}$ & $18 \pm 10$ & $15 \pm 8$ & NS \\
pHuv $_{\mathrm{PuvO}_{2}} \mathrm{kPa}$ & $7.35 \pm 0.07$ & $7.36 \pm 0.04$ & NS \\
$\quad(\mathrm{mmHg})$ & $3.7 \pm 1.0$ & $4.25 \pm 1.0$ & NS \\
$\mathrm{SuvO}_{2}$ & $(26.8 \pm 7.2)$ & $(30.6 \pm 7.5)$ & \\
\hline
\end{tabular}

Values given are mean $\pm \mathrm{SD}$.

during labour or Caesarean section as well as with mechanical ventilation during Caesarean section under general anaesthesia. ${ }^{1,2,4,5}$ Although initial reports suggested that there were no further increases in fetal oxygen pressures as matemal $\mathrm{PaO}_{2}$ was increased beyond $40 \mathrm{kPa}$ $(300 \mathrm{mmHg})^{5}$ later studies demonstrated continued increases in fetal $\mathrm{PO}_{2}$ without evidence of a ceiling effect. ${ }^{3}$

The term fetus is well adapted to low blood oxygen tensions. At birth the haemoglobin of the term neonate is $65-85 \%$ haemoglobin $\mathrm{F}(\mathrm{HbF})$ which has an increased affinity for oxygen, binding it more avidly than does adult haemoglobin $(\mathrm{HbA})$. The oxy-haemoglobin dissociation curve for $\mathrm{HbF}$ is left-shifted compared with that of $\mathrm{HbA}$, the result being that $\mathrm{HbF}$ is more fully saturated than $\mathrm{HbA}$ at lower oxygen tensions. In addition, the fetus is relatively polycythaemic (haematocrit $>45$ ) and the overall result is that the blood oxygen content is higher than it would be in the adult under similar oxygen tensions. Despite these adaptive changes, fetal oxygen reserves are quite limited at birth although clinically important increases may be registered by providing the mother with increased $\mathrm{FlO}_{2}{ }^{2}$

The optimal level of fetal oxygen action before delivery during normal Caesarean section is not known. Increased fetal oxygen content may act as a reservoir permitting the fetus to withstand better the reduced placental perfusion that might result from aortocaval compression, decreased maternal blood pressure following induction of an epidural block or the decrease in uterine blood flow following uterine incision at Caesarean section. As well, the neonate may be better able to withstand postnatal apnoea or oxygen deprivation for longer periods. In fetal lamb models, providing the mother with supplemental oxygen increased oxygen delivery to the fetus during times of decreased umbilical blood flow and provided an oxygen reserve with which the fetus could maintain aerobic metabolism. ${ }^{6}$ Although oxygen extraction ratios increase with decreasing umbilical flow, fetal oxygen consumption may be maintained with reduction of umbilical blood 
flows to $50 \%$ of control values if the mother is provided a supplemental source of oxygen. The lamb fetus will withstand umbilical flow reductions that are $50 \%$ greater without reducing oxygen consumption if the mother is provided supplemental oxygen compared to when she inspires room air. Thus, providing the mother with supplemental oxygen may allow the fetus to withstand better the stresses on the placental circulation during Caesarean section.

Assessment of the infant immediately after birth should provide some indication to the adequacy of the placental unit in maintaining adequate fetal acid-base balance and oxygenation. However, the instruments which should be employed to make the determination of placental sufficiency is not clear. Apgar scores were originally designed to assess the need and extent of neonatal resuscitation and high scores $(\geq 7)$ are neither sensitive nor specific in predicting normal fetal acid-base balance. ${ }^{8}$ However, scores above 7 at one minute generally predict a low likelihood of the need for intervention and a good neonatal outcome. The interpretation of fetal blood $\mathrm{pH}$ is difficult because, although normal $\mathrm{pH}$ predicts a good outcome, many well babies are acidotic when assessed by cord $\mathrm{pH}$ and thus an acidotic $\mathrm{pH}$ does not necessarily predict a sick baby. ${ }^{9}$

How, then, should the fetal effect of supplemental oxygen delivered to the mother during Caesarean section be assessed? The Apgar score will provide some indication to the need for support and intervention in the period immediately after delivery. As well, measurement of fetal $\mathrm{pH}, \mathrm{SuvO}_{2} / \mathrm{PuvO}_{2}$, and $\mathrm{PuaO}_{2} / \mathrm{SuaO}_{2}$, will provide an assessment of the adequacy of fetal oxygen supply immediately before delivery and its ability to maintain aerobic metabolism. There was no difference between both the mean Apgar scores at one and five minutes in our neonates who had Apgar scores $<7$ at one or five minutes nor was there a difference between the groups with respect to fetal $\mathrm{pH}$ or oxygen variables. This suggests that, overall, the condition of the infants was good, comparable between the two groups and was not influenced by whether the mother received oxygen via nasal prongs or facemask. We conclude that, at the evaluated levels of oxygen flow, it makes little difference whether the mother receives oxygen through simple facemask or nasal prongs.

We conclude that when the clinical condition as well as the acid-base and oxygen status of neonates, delivered by Caesarean section to mothers under epidural anaesthesia, are evaluated, it makes no difference whether the mothers receive supplemental oxygen via nasal prongs or facemask. Our findings and conclusions relate to elective Caesarean sections in mothers who do not have conditions associated with compromised placental function and do not necessarily apply to the patients with conditions which may lead to abnormal placental function.

\section{Acknowledgment}

The authors would like to thank Sylvie Paquette for typing , this manuscript.

\section{References}

1 Fox GS, Houle GL. Acid-base studies in elective Caesarean sections during epidural and general anaesthesia. Can Anaesth Soc J 1971; 18: 60-71.

2 Marx $G F$, Mateo $C V$. Effects of different oxygen concentrations during general anaesthesia for elective Caesarean section. Can Anaesth Soc J 1971; 18: 587-93.

3 Ramanathan S, Gandhi S, Arismendy J, Chalon J, Turndorf $H$. Oxygen transfer from mother to fetus during cesarean section under epidural anesthesia. Anesth Analg 1982; 61: 576-81.

4 Willcourt RJ, King JC, Queenan JT. Maternal oxygenation administration and the fetal transcutaneous $\mathrm{PO}_{2}$. Am J Obstet Gynecol 1983; 146: 714-5.

5 Baraka A. Correlation between maternal and foetal $\mathrm{PO}_{2}$ and $\mathrm{PCO}_{2}$ during Caesarean section. $\mathrm{Br} \mathrm{J}$ Anaesth 1970; 42: 434-8.

6 Edelstone DI, Peticca BB, Goldblum $L J$. Effects of maternal oxygen administration on fetal oxygenation during reductions in umbilical blood flow in fetal lambs. Am J Obstet Gynecol 1985; 152: 351-8.

7 Itskovitz J, Lagamma EF, Rudolph AM. The effect of reducing umbilical blood flow on fetal oxygenation. Am J Obstet Gynecol 1983; 145: 813-8.

8 Vintzileos AM, Gaffney SE, Salinger LM, Kontopoulos VG, Campbell WA, Nochimson DJ. The relationships among the fetal biophysical profile, umbilical cord $\mathrm{pH}$, and Apgar scores. Am J Obstet Gynecol 1987; 157 : 627-31.

9 Josten BE, Johnson TRB, Nelson JP. Umbilical cord blood $\mathrm{pH}$ and Apgar scores as an index of neonatal health. Am J Obstet Gynecol 1987; 157: 843-8. 